\title{
Stage IIIB Anal Canal Cancer AJCC v6 and v7
}

National Cancer Institute

\section{Source}

National Cancer Institute. Stage IIIB Anal Canal Cancer A/CC v6 and v7. NCI Thesaurus. Code C5926.

Stage IIIB includes: (T4, N1, M0); (Any T, N2, M0); (Any T, N3, M0). T4: T umor of any size that invades adjacent organ(s). N1: Metastasis in perirectal lymph node(s). N2: Metastasis in unilateral internal iliac and/or inguinal lymph node(s). N3: Metastasis in perirectal and ing uinal lymph nodes and/or bilateral internal iliac and/or inguinal lymph nodes. M0: No distant metastasis. (AJCC 6th and 7th Eds.) 